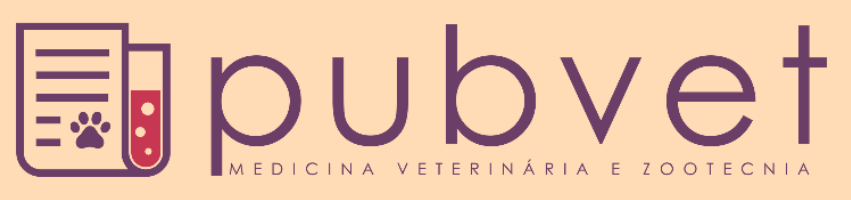

https://doi.org/10.31533/pubvet.v15n02a744.1-10

\title{
O controle microbiológico da qualidade de alimentos
}

\author{
Ariane Marinho Mendes $^{10}$, Laryssa Freitas Ribeiro ${ }^{20}$ \\ ${ }^{I}$ Aluno do Curso de Pós-Graduação da Universidade Cândido Mendes, Rio de Janeiro, Brasil \\ ${ }^{2}$ Professora do Centro Universitário Mário Palmério, Monte Carmelo, Minas Gerais. \\ *Autor para correspondência, E-mail: ariane.rj@ibest.com.br
}

\begin{abstract}
Resumo. O aumento da população mundial faz com que aumente também a necessidade de se produzir alimentos de qualidade considerando que esse é um fator que pode afetar diretamente a condição de saúde humana. A cadeia produtiva de alimentos está intimamente relacionada com a Saúde Pública, a qual atua dando suporte técnico, fiscalizando e orientando os produtores em todos os pontos críticos desse sistema, sendo assim o controle microbiológico, físico-químico e sensorial são extremamente importantes por serem ações fundamentais na garantia da qualidade dos alimentos oferecidos para a população. Mas, para que possamos garantir essa qualidade, os laudos laboratoriais precisam ser confiáveis, por isso é necessário que os profissionais sejam providos de recursos adequados, pessoal capacitado, e tenham a preocupação de se manter sempre atualizados com relação às metodologias mais adequadas a cada análise, aos procedimentos analíticos e critérios de qualidade. Tal constatação levou ao interesse em se fazer uma revisão de literatura sobre as metodologias utilizadas para identificação e diagnóstico dos principais microrganismos causadores de doenças transmitidas por alimentos na população humana, buscando disponibilizar material capaz de contribuir na atualização e capacitação dos profissionais que atuam na área devido à preocupação com eficiência da sua assistência no âmbito da Saúde Pública.
\end{abstract}

Palavras chave: Microbiologia, físico-química, vigilância sanitária, zoonoses

\section{Microbiological control of food quality}

Abstract. The increase in the world population also increases the need to produce quality food considering that this is a factor that can directly affect the condition of human health. The food production chain is closely related to Public Health, which acts by providing technical support, supervising and guiding producers at all critical points of this system, so microbiological, physical-chemical and sensory control are extremely important because they are actions fundamental in guaranteeing the quality of the food offered to the population. However, in order for us to guarantee this quality, laboratory reports must be reliable, so it is necessary that professionals are provided with adequate resources, trained personnel, and are concerned with always keeping up to date with the most appropriate methodologies for each analysis to analytical procedures and quality criteria. This finding led to the interest in conducting a literature review on the methodologies used to identify and diagnose the main microorganisms that cause foodborne diseases in the human population, seeking to provide material capable of contributing to the updating and training of professionals working in the area due concern with the efficiency of its assistance in the scope of Public Health.

Keywords: Microbiology, physicochemical, health surveillance, zoonoses 


\section{Control microbiológico de la calidad de los alimentos}

Resumen. El aumento de la población mundial también incrementa la necesidad de producir alimentos de calidad considerando que este es un factor que puede afectar directamente la condición de la salud humana. La cadena de producción de alimentos está estrechamente relacionada con la Salud Pública, la cual actúa brindando apoyo técnico, supervisando y orientando a los productores en todos los puntos críticos de este sistema, por lo que el control microbiológico, físico-químico y sensorial son de suma importancia por ser acciones fundamentales para garantizar la calidad de los alimentos ofrecidos a la población. Sin embargo, para que podamos garantizar esta calidad, los informes de laboratorio deben ser confiables, por lo que es necesario que los profesionales cuenten con los recursos adecuados, personal capacitado, y se preocupen por estar siempre actualizados con las metodologías más adecuadas para cada análisis de procedimientos analíticos y criterios de calidad. Este hallazgo motivó el interés de realizar una revisión de la literatura sobre las metodologías utilizadas para identificar y diagnosticar los principales microorganismos causantes de enfermedades de transmisión alimentaria en la población humana, buscando brindar material capaz de contribuir a la actualización y capacitación de los profesionales que laboran en el área debido preocupación por la eficiencia de su asistencia en el ámbito de la Salud Pública.

Palabras clave: Microbiología, fisicoquímico, vigilancia de la salud, zoonosis

\section{Introdução}

A ingestão de alimentos ou água contaminados pode levar ao desenvolvimento do que conhecemos como Doenças Transmitidas por Alimentos (DTA's) (Malacrida et al., 2017; Melo et al., 2018), cujos principais sintomas são: anorexia, náuseas, vômitos e/ou diarreia, dependendo muito do agente etiológico envolvido. São mais de 250 doenças diferentes. Os principais agentes etiológicos são bactérias, toxinas, fungos, vírus, príons, agrotóxicos, produtos químicos, metais pesados e parasitos (Welker et al., 2010). Não existem vacinas para esse tipo de doenças. O combate às estas enfermidades é um fator extremamente importante para o turismo (Portal da Saúde SUS-MS, 2016).

Essas doenças vêm surgindo como um grande problema de saúde pública em muitos lugares do mundo, sendo importantes fatores de morbidade e mortalidade (Melo et al., 2018). Além disso, acreditase que o problema ainda vai aumentar muito devido a produção de a distribuição de alimentos em larga escala como consequência do grande crescimento populacional, principalmente no grupo de pessoas vulneráveis, a pobreza potencializada pela rápida urbanização em áreas sem infraestrutura de saneamento básico, aumento de viagens bem como também do comércio internacional de alimentos e rações, e a falta de conhecimento sobre o tema. Todas essas mudanças globais incluindo a modificação nas práticas de preparo dos alimentos (Hasler, 1998).

Para Araújo (2004), esses surtos podem ser investigados pela identificação etiológica laboratorial, porém relatos nacionais e internacionais demonstram que a maioria dos casos não é notificada porque causam sintomas brandos. Os casos notificados se restringem aos que envolvem um maior número de pessoas, ou quando a duração dos sintomas é mais prolongada. Sabendo que todos os casos de eventos que caracterizem ameaçam a saúde pública devem ser notificados, conforme determina a Portaria $\underline{\text { SVS/MS n }}{ }^{\circ} 204$, de 17/02/2016, e essa notificação se dá apelo SINAN.

Segundo Franco \& Landgraf (1996) e Hocquette et al. (2005), os cuidados e o controle da qualidade dos alimentos devem começar ainda na propriedade rural, passando pela indústria durante o seu processamento, atentando para todos os pontos inclusive o transporte, estocagem, comercialização e preparo, seja no domicílio ou em estabelecimentos comerciais. Os microrganismos estão em todos os lugares, inclusive nos alimentos, e tem a capacidade de crescer e se multiplicar muito rapidamente em condições favoráveis. Por isso é muito importante a realização do controle microbiológico dos alimentos oferecidos a população, assegurando sua qualidade higiênico sanitária, e prevenindo as DTA's. Para tanto, a RDC 12 de 02 de janeiro de 2001 da ANVISA visando a proteção da saúde da população regulamenta os critérios e define os padrões microbiológicos para alimentos, indispensáveis para avaliação das Boas Práticas de Produção de Alimentos e Prestação de Serviços. 
Franco \& Landgraf (1996) nos dizem ainda que “A presença microbiana é considerada como o grande desafio da indústria em produzir alimentos seguros/inócuos". E, sendo assim o controle da qualidade microbiológica precisa ser eficaz na caracterização da conformidade analítica segundo os regulamentos de identidade e qualidade vigentes no país, levando em consideração a representatividade da partida ou do lote, a fidedignidade dos procedimentos analíticos, a eficiência e qualificação do analista e o tempo da emissão dos resultados.

Ademais, para a realização das análises de acordo com a conformidade analítica prevista é necessária a elaboração de Procedimento Operacional Padrão (POP's). De acordo com O Manual de Procedimento Operacional Padrão da ANVISA (2016) trata-se de um documento interno que determina a metodologia utilizada para a realização de cada análise, através da sistematização e descrição detalhada de cada procedimento analítico, relacionando os materiais necessários, seus equipamentos, meios de cultura, descrevendo o princípio da análise a ser feita, sua relevância social, e os passos que devem ser seguidos para a realização dos ensaios. Esse documento serve para orientar os profissionais a respeito de qualquer dúvida que possa surgir na realização dos procedimentos, e garantir a equidade em todas as análises, bem como a sua eficácia minimizando a ocorrência de desvios na execução das análises independente de quem as faça. Ele é a base para a garantia da padronização e a garantia de um serviço livre de variações indesejáveis, seguindo as metodologias analíticas mais satisfatórias e adequadas para o processamento de amostras. Mas torna necessário revisar e aprovar previamente os procedimentos selecionados para se tornarem padrão dentro da rotina laboratorial.

Diante disso, o presente artigo visa realizar uma revisão de literatura sobre a microbiologia de alimentos, descrevendo a sua importância no controle de qualidade dos alimentos, identificando os principais microrganismos patogênicos de importância alimentar, a principal metodologia de detecção laboratorial e analisando os critérios desse controle. Esse assunto possui grande interesse na Medicina Veterinária visto que o controle da qualidade dos alimentos disponibilizados para a população em geral está diretamente relacionado com sua saúde e qualidade de vida. E, por tanto tem muita relevância no que tange a saúde pública, além de se desdobrar em diversos nichos de atuação profissional para o médico veterinário.

"Um procedimento coerente garante ao usuário que a qualquer momento que ele se dirija ao laboratório, as ações tomadas na fase pré-analítica, analítica e pós-analítica críticas para garantir a qualidade de seus exames sejam as mesmas, de uma rodada para a outra, de um turno para outro, de um dia para outro. Ou seja, aumenta-se a previsibilidade de seus resultados, minimizando as variações causadas por imperícia e adaptações aleatórias da metodologia, independente de falta, ausência parcial ou férias de um funcionário". (Manual de Procedimento Operacional Padrão - ANVISA, 2016)

\section{A importância do controle microbiológico na qualidade de alimentos}

A importância dos microrganismos nos alimentos vai além da sua patogenicidade. De acordo com Franco \& Landgraf (1996) eles podem desempenhar papéis muito importantes, sendo possível classificálos em três grupos distintos, os microrganismos causadores de "deterioração microbiana"; os microrganismos patogênicos, que representam risco à saúde; e os microrganismos capazes de causar alterações benéficas em um alimento, modificando suas características originais. Porém, para fins deste artigo será discutido apenas aqueles causadores de patogenicidade, bem como sua principal metodologia de detecção laboratorial.

Segundo Forsythe (2013), muitos fatores contribuem para que os alimentos não sejam seguros e causem doenças, sendo as principais causas controle inadequado da temperatura durante a estocagem, cozimento, e os resfriamento; higiene pessoal insuficiente; contaminação cruzada entre produtos crus e processados; e o monitoramento inadequado dos processos, fatores que podem ser reduzidos de forma considerável capacitando adequadamente a equipe e implementando o sistema APPCC combinado com a avaliação de riscos.

Para compreendermos melhor a ação desses agentes na transmissão de doenças faz-se importante conhecer algumas definições. De acordo com Portal da Saúde (SUS - MS, 2019) infecções transmitidas por alimentos são doenças que resultam da ingestão de um alimento que contenha organismos prejudiciais à saúde; já as intoxicações alimentares ocorrem quando uma pessoa ingere alimento com 
substâncias tóxicas, incluindo toxinas produzidas por bactérias e fungos; enquanto que toxinfecção causada por alimentos é caracterizada pela ingestão de alimentos que apresentam organismos prejudiciais à saúde e que liberam toxinas.

A produção de alimentos para uma população que cresce assustadoramente é o desafio do século. A produção agrícola aumenta os riscos de ataque por pragas e doenças, tendo em vista que a epidemiologia nos demonstra que sempre que há um acúmulo de indivíduos de uma mesma espécie em contato próximo isso aumenta as chances de transmissão de agentes de doenças e a multiplicação de parasitos. Logo fazse necessária a implementação de medidas preventivas destinadas a evitar ou a controlar os prejuízos decorrentes da ação desses agentes nocivos (ANVISA, 2013; Tortora et al., 2017). E para isso é importante que possamos conhecer os principais microrganismos de importância na transmissão de doenças por alimentos e também as principais formas de identificar sua presença no que consumimos.

\section{Salmonella spp}

A salmonela pertence à família Enterobacteriaceae é um bastonete gram-negativo, aeróbio e anaeróbio facultativo, oxidase negativos e é patogênica. Não fermenta a lactose, é amplamente distribuída na natureza, podendo estar presente no solo, na água, nos animais, nos seres humanos, e em suas fezes (Bruha et al., 2014; Silva et al., 2010).

De acordo com o Manual Técnico de Diagnóstico laboratorial da Salmonella spp (MS, 2011), o gênero é constituído de duas espécies, a $S$. enterica e $S$. bongori, sendo que a primeira é subdividida em seis subespécies. Além disso, atualmente são reconhecidos cerca de 2500 sorovares diferentes, incluídos nas duas espécies. Geralmente são móveis, e capazes de formar ácido, e na prova de Voges-Proskauer (VP), vermelho de metila (VM), malonato e ureia negativa (Krämer et al., 2011). O mesmo manual (MS, 2011) ainda relata que são altamente adaptadas ao homem e aos animais, tendo sua distribuição mundial. Os alimentos são o principal veículo de sua transmissão, sendo responsáveis por índices de morbidade significativos, bem como de mortalidade, causando pequenos e grandes surtos, tanto em países em desenvolvimento, como nos desenvolvidos. Os alimentos mais envolvidos em surtos são de origem animal como ovos, aves, carnes e produtos lácteos (Ahmed \& Shimamoto, 2014).

De acordo com os padrões microbiológicos definidos pela RDC 12 (ANVISA, 2013) a análise para Salmonella spp vai identificar presença ou ausência em $25 \mathrm{~g}$ de amostra. A metodologia utilizada é descrita no Manual de Métodos de Análise Microbiológica de Alimentos e Água (Silva et al., 2010) e ela tem inicialmente três fases, a de enriquecimento, a de enriquecimento seletivo, e a de plaqueamento. Caso haja o crescimento de colônias sugestivas de salmonela, faz-se a triagem bioquímica e as análises bioquímicas para diferenciação da espécie. No pré-enriquecimento pesa-se $25 \mathrm{~g}$ de amostra homogeneizada, e dilui-se em $225 \mathrm{~mL}$ de CLS (Caldo Lactosado Simples), em seguida deve-se homogeneizar e incubar a $35^{\circ} \mathrm{C} \pm 1^{\circ} \mathrm{C}$, por 24 horas. Após esse período se segue o enriquecimento seletivo, em tubos com caldo tetrationato e rapapport. Antes de iniciar essa etapa é necessário suplementar o caldo tetrationato com $0,1 \mathrm{~mL}$ de solução verde brilhante a $1 \%$, e $0,2 \mathrm{~mL}$ de solução de iodeto de potássio. Para então repicar no tetrationato $1,0 \mathrm{~mL}$ da amostra pré-enriquecida no CLS, e 0,1 $\mathrm{mL}$ no tubo contendo o caldo rapapport. Esses tubos devem ser incubados respecitavamente a $35^{\circ} \mathrm{C} \pm$ $1^{\circ} \mathrm{C}$, e a $42^{\circ} \mathrm{C} \pm 0,2^{\circ} \mathrm{C}$ por mais 24 horas. A próxima etapa é o plaqueamento, quando cada tubo da etapa anterior será repicado em 3 placas de petri contendo respectivamente Agar xilose lisina desoxicolato (XLD), Mac Conkey e Hektoen, que deverão ser incubadas na posição invertida a $35^{\circ} \mathrm{C} \pm 1^{\circ} \mathrm{C}$, por mais 24 horas. Para a leitura são consideradas suspeitas de Salmonella as placas XLD que apresentarem colônias transparentes, ou cor rosa escura, com ou sem centro negro; as placas de Hektoen com colônias transparentes, verde azuladas, com ou sem centro negro; e as placas Mac Conkey com colônias transparentes, com ou sem centro negro, que apresentem clareamento da zona de precipitação ao redor das colônias e mudança da cor do meio para amarelo.

Caso ocorra o crescimento colônias em alguma das placas que sigam essa descrição deve-se selecionar algumas dessas colônias para repique e confirmação pela triagem bioquímica em pequenos tubos contendo Agar Triple sugar iron (TSI), Agar Iron Lisina (LIA), e caldo ureia nessa ordem. Uma vez repicados, deve-se incubar a $35^{\circ} \mathrm{C} \pm 2^{\circ} \mathrm{C}$, por 24 horas e em seguida proceder a leitura considerando que a mudança do meio para amarelo indica reação ácida, e a mudança para vermelho violeta, indica reação alcalina. A correlação entre os resultados ácidos ou alcalinos irá determinar se o resultado é 
compatível com a possível presença de Salmonela, o que torna necessária a confirmação através dos testes bioquímicos, sendo eles o teste do Indol, do citrato, VM-VP, testes de sorologia, e o teste de motilidade realizado no Agar Indol Sulfeto Motilidade (SIM). Caso alguma dessas provas não apresente resultado compatível com o padrão esperado para esse microrganismo a amostra será considerada isenta com resultado de ausência em $25 \mathrm{~g}$.

\section{Coliformes totais e termotolerantes}

Para Iamanaka et al. (2013), coliformes totais também é um subgrupo da família Enterobacteriaceae, e compreende apenas as enterobactérias capazes de fermentar a lactose com produção de gás em 24-48 horas, a $35^{\circ} \mathrm{C}$. Entre as espécies que se encaixam nessa descrição estão as originárias do trato gastrintestinal de humanos e outros animais de sangue quente, como também bactérias não entéricas como Citrobacter spp, Enterobacter spp, Klebsiella spp e Serratia spp, dentre outras. Já o grupo dos coliformes termotolerantes, comumente chamados de coliformes fecais, é um subgrupo dos coliformes totais, restrito aos membros capazes de fermentar a lactose em 24 horas, entre $44,5-45,5^{\circ} \mathrm{C}$, com produção de gás. É conhecido que esse grupo também pode abranger espécies de origem não fecal, e por essa razão o termo "coliformes fecais" vem sendo substituído por coliformes termotolerantes, segundo a resolução $n^{\circ} 375$ do CONAMA, 2005.

Segundo Franco \& Landgraf (2003), em 1892 foi proposto o uso de E. coli como indicador da contaminação de origem fecal por atender à alguns requisitos, ter o trato intestinal do homem e outros animais como habitat exclusivo; estando presente em fezes; apresentar alta resistência ao ambiente extra intestinal; e por haver técnicas rápidas, simples e precisas para sua detecção e/ou contagem. Dessa forma, quando presentes em números elevados nos alimentos, podem causar deterioração, e suas contagens podem nos fornece informações gerais sobre as condições higiênicas do alimento.

A metodologia utilizada é descrita no Manual de Métodos de Análise Microbiológica de Alimentos e Água (Silva et al., 2010). Para realização dessa análise deve ser observado o padrão microbiológico determinado pela RDC 12 de 2001 da ANVISA, no que diz respeito ao limite de tolerância da presença dessas bactérias. Esse limite de tolerância definirá a diluição a partir da qual se iniciará a análise. Pesase $25 \mathrm{~g}$ da amostra que deve ser diluída em $225 \mathrm{~mL}$ de água fosfatada peptonada (AFT), a qual será a diluição de $10^{-1}$ da qual serão obtidas todas as outras diluições necessárias transferindo $1 \mathrm{~mL}$ para um tubo contendo $9 \mathrm{~mL}$ de AFT para a diluição $10^{-2}$. Esse procedimento será repetido sucessivamente para a obtenção das diluições subsequentes em potência de 10, tantas vezes quantas forem necessárias afim de tornar possível a análise de 3 diluições seriadas da amostra considerando a diluição inicial. Cada diluição deverá ser semeada sempre em triplicata, transferido $1 \mathrm{~mL}$ para o tubo contendo o Caldo Lactosado Simples (CLS) que deverão ser incubados a $35^{\circ} \mathrm{C}$ por 48 horas. Será positivo se, após o período de incubação apresentar formação de gás no tubo de Durhan e/ou efervescência dentro do tubo.

\begin{tabular}{|c|c|c|c|c|c|c|c|c|c|c|c|}
\hline \multicolumn{3}{|c|}{ Pos. Tubes } & \multicolumn{3}{|c|}{ Conf. lim. } & \multicolumn{3}{|c|}{ Pos. tubes } & \multicolumn{3}{|c|}{ Conf. lim. } \\
\hline 0.10 & 0.01 & 0.001 & MPN/8 & Low & High & 0.10 & 0.01 & 0.001 & $\mathrm{MPN} / \mathrm{B}$ & Low & High \\
\hline 0 & 0 & 0 & $<3.0$ & - & 9.5 & 2 & 2 & 0 & 21 & 4.5 & 4 \\
\hline 0 & 0 & 1 & 3.0 & 0.15 & 9.6 & 2 & 2 & 1 & 28 & 8.7 & 9 \\
\hline 0 & 1 & 0 & 3.0 & 0.15 & 11 & 2 & 2 & 2 & 35 & 8.7 & 9 \\
\hline 0 & 1 & 1 & 6.1 & 1.2 & 18 & 2 & 3 & 0 & 29 & 8.7 & 9 \\
\hline 0 & 2 & 0 & 6.2 & 1.2 & 18 & 2 & 3 & 1 & 36 & 8.7 & 9 \\
\hline 0 & 3 & 0 & 9.4 & 3.6 & 38 & 3 & 0 & 0 & 23 & 4.6 & 9 \\
\hline
\end{tabular}

Tabela 1- Continua 


\begin{tabular}{|c|c|c|c|c|c|c|c|c|c|c|c|}
\hline \multicolumn{3}{|c|}{ Pos. Tubes } & \multicolumn{3}{|c|}{ Conf. lim. } & \multicolumn{3}{|c|}{ Pos. tubes } & \multicolumn{3}{|c|}{ Conf. lim. } \\
\hline 0.10 & 0.01 & 0.001 & MPN/8 & Low & High & 0.10 & 0.01 & 0.001 & $\mathrm{MPN} / \mathrm{g}$ & Low & High \\
\hline 1 & 0 & 0 & 3.6 & 0.17 & 18 & 3 & 0 & 1 & 38 & 8.7 & 110 \\
\hline 1 & 0 & 1 & 7.2 & 1.3 & 18 & 3 & 0 & 2 & 64 & 17 & 180 \\
\hline 1 & 0 & 2 & 11 & 3.6 & 38 & 3 & 1 & 0 & 43 & 9 & 180 \\
\hline 1 & 1 & 0 & 7.4 & 1.3 & 20 & 3 & 1 & 1 & 75 & 17 & 200 \\
\hline 1 & 1 & 1 & 11 & 3.6 & 38 & 3 & 1 & 2 & 120 & 37 & 420 \\
\hline 1 & 2 & 0 & 11 & 3.6 & 42 & 3 & 1 & 3 & 160 & 40 & 420 \\
\hline 1 & 2 & 1 & 15 & 4.5 & 42 & 3 & 2 & o & 93 & 18 & 420 \\
\hline 1 & 3 & 0 & 16 & 4.5 & 42 & 3 & 2 & 1 & 150 & 37 & 420 \\
\hline 2 & 0 & 0 & 9.2 & 1.4 & 38 & 3 & 2 & 2 & 210 & 40 & 430 \\
\hline 2 & 0 & 1 & 14 & 3.6 & 42 & 3 & 2 & 3 & 290 & 90 & 1,000 \\
\hline 2 & 0 & 2 & 20 & 4.5 & 42 & 3 & 3 & 0 & 240 & 42 & 1,000 \\
\hline 2 & 1 & 0 & 15 & 3.7 & 42 & 3 & 3 & 1 & 460 & 90 & 2,000 \\
\hline 2 & 1 & 1 & 20 & 4.5 & 42 & 3 & 3 & 2 & 1100 & 180 & 4,100 \\
\hline 2 & 1 & 2 & 27 & 8.7 & 94 & 3 & 3 & 3 & $>1100$ & 420 & - \\
\hline
\end{tabular}

Os tubos positivos serão repicados em caldo EC, que deverão ser colocados em banho Maria, ou estufa a $45^{\circ}$ durante 48 horas, após o que deverá ser feita a leitura. Esta será positiva se persistir a formação de gás no interior do tubo de Durhan, e/ou com efervescência do caldo. A unidade de medida dos resultados será em número mais provável (NMP/g), e chega-se a esse valor através da tabela de número mais provável.

\section{Contagem de Clostridium sulfito redutores a $46^{\circ} \mathrm{C}$}

Conforme descrevem Silva et al. (2010), Clostridium perfringens é gram positivo, na forma de bastonetes, anaeróbias estritas e imóveis. Esporulam facilmente no intestino, e são sulfito redutoras e fermentam lactose. Também reduzem o nitrato e hidrolisam a gelatina, seu $\mathrm{pH}$ ótimo é 7,2, mas podem apresentar crescimento entre 5,5 e 9,0. Morrem rapidamente entre $0^{\circ}$ e $10^{\circ} \mathrm{C}$, pois são muito sensíveis a variações de temperatura. É capaz de produzir uma série de toxinas, porém cada cepa produz apenas um número limitado delas. Por isso são classificadas em A, B, C, D e E de acordo com a sua capacidade de produzir as 4 toxinas mais letais dentre as suas possibilidades, as toxinas alfa, beta, épsilon e iota.

Ainda de acordo com sua descrição as condições ácidas do estômago e a presença de sais biliares estimulam a produção de uma enterotoxina pelo $C$. perfringens, essa enterotoxina provoca uma desordem intestinal com cólica abdominal, diarreia e náuseas, geralmente sem vômito ou febre que pode durar até paciente. Mas não se pode esquecer que, como é muito sensível a baixa temperatura, ele pode não ser detectado em alimentos que foram resfriados ou congelados por período de tempo prolongado. Quando isso acontecer, a solução é a verificação de esfregaços do alimento e coloração de Gram, buscando os bastonetes grandes, típicos do Clostrídium perfringens. Esse microrganismo é altamente distribuído no solo, poeira e vegetação, além de estar presente normalmente no intestino do homem, e dos animais sem nenhum envolvimento clínico. Em idosos saudáveis é muito comum encontrarmos contagens elevadas de esporos nas fezes. Os alimentos mais envolvidos com surtos são as carnes, cozidas ou assadas preparadas em grande quantidade e mantidos de um dia para o outro, pois os esporos sobrevivem à temperatura de cozimento e com esse resfriamento lento ele pode se multiplicar. 
A toxina beta se ingerida, pode provocar uma doença séria e muito mais rara. uma enterite necrótica com septicemia, a qual frequentemente evolui para o óbito do paciente. Ela é sensível à tripsina, mas a batata doce contém um inibidor da tripsina que predispõe à doença, principalmente crianças e adolescentes que tenham como base da sua dieta esse vegetal. A fome e a desnutrição também reduzem o nível da tripsina, e aumentam a predisposição às intoxicações beta.

Em Franco \& Landgraf (2003) verificamos que uma das doenças que podem ser causadas por clostridios é o botulismo. Esta doença possui um período de incubação que varia entre 12 a 36 horas, dependendo da quantidade de toxina ingerida. Inicialmente apresenta sintomas gastrintestinais gerais, seguidos pela ação da neurotoxina que provoca fadiga e fraqueza muscular, acompanhados de problemas de visão, queda das pálpebras, resposta alterada da pupila à luz, visão dupla, secura da boca, dificuldade de deglutição e de controle da língua. A musculatura que controla a respiração é progressivamente paralisada, podendo provocar a morte em 3 a 5 dias por parada respiratória. Além disso, outras espécies podem causar toxinfecção alimentar que podem ser graves.

Para a identificação deste microrganismo em alimentos existem vários meios de cultura, sua seletividade depende da adição de um ou mais antibióticos para inibir as competidoras, e a presença de ferro e sulfito. Os clostridios sulfito redutores reduzem o sulfito a sulfeto de hidrogênio que reage com o ferro e produz colônias pretas.

A metodologia utilizada é descrita no Manual de Métodos de Análise Microbiológica de Alimentos e Água (Silva et al., 1997), segundo a qual será depositado $1 \mathrm{~mL}$ de diluição da amostra em uma placa de petri, para cada uma das diluições $10^{-3}, 10^{-4}$ e $10^{-5} \mathrm{e}$ em seguida adiciona-se o meio Agar Clostridium Perfringens, do inglês Shahidi Ferguson Perfringens (SFP) pela técnica de pour plate. Por se tratar de um anaeróbio obrigatório, adiciona-se uma segunda camada de Agar. Na sequência as placas introduzidas numa jarra de anaerobiose juntamente com o gerador de anaerobiose. Depois de hermeticamente fechada, a jarra é incubada a $46^{\circ} \mathrm{C}$ por 24 horas. As colônias típicas apresentam centro negro, e, se ocorrerem, devem ser contadas e multiplicadas pela diluição.

\section{Contagem de Bacillus cereus}

São bastonetes gram positivos, esporogênicos, aeróbios e anaeróbios facultativos. Comumente encontrados no solo, em vegetais e em muitos alimentos crus ou processados. Suas cepas são catalase positivas e capazes de decompor tirosina. Sua temperatura ótima de crescimento é entre $30^{\circ}$ e $40^{\circ} \mathrm{C}$ e o pH ótimo varia entre 6,0-7,0. Seus esporos apresentam resistência térmica similar a outros esporos de bactérias mesófilas, e causam intoxicações que podem levar a dois tipos de doenças: uma síndrome diarreica, e uma síndrome emética. Os alimentos mais frequentemente envolvidos em surtos são ricos em proteínas ou amido cozidos, como arroz, massas, sopas, saladas de vegetais, brotos de sementes, pudins e carnes. Tanto o cozimento como a refrigeração inadequada podem ativar os esporos levandoos a germinar e produzir toxinas (Silva et al., 1997).

Forsythe (2013) relata que este microrganismo apresente duas formas morfológicas, sendo elas o endósporo e a célula vegetativa, sem do estas últimas classificadas como anaeróbias facultativas. Diz também que tem distribuição ubiquitária na natureza, e que devido à sua capacidade de formar esporos resistentes a condições adversas ele pode permanecer viável durante longos períodos de tempo no ambiente e nos alimentos. Para que ocorra a ativação do esporo e ele volte à sua forma vegetativa é necessária uma ativação que pode se dar por uma mudança na temperatura, ou um aumento na disponibilidade de fontes de carbono.

De acordo com o Manual de Métodos de Análise Microbiológica de Alimentos e Água (Silva et al., $\underline{2010}$ ) a metodologia utilizada é plaqueamento em superfície, e são utilizadas diluições $10^{-2}, 10^{-3}, 10^{-4}$ das quais são retirados $0,1 \mathrm{~mL}$ e depositados respectivamente em placas de à gar Manitol-Gema de ovoPolimixina (MYP). Com o auxílio da alça de Drigaslski a alíquota deve ser espalhada pela superfície do Agar até que seja completamente absorvida. Incubar a $\pm 30^{\circ}$ a $32^{\circ} \mathrm{C}$ por \pm 24 horas, em caso de crescimento de colônias típicas, rosas e grandes, seguir para a bioquímica.

Para a confirmação deve-se selecionar pelo menos 3 colônias típicas e estriar em dois tubos com Agar nutriente para cada colônia. Em seguida serão incubados novamente a $\pm 30^{\circ}$ a $32^{\circ} \mathrm{C}$ por \pm 24 horas. Após esse período, um dos tubos de cada colônia será disposto em ambiente por 3 dias. O outro tubo servirá para 
a constituição de um soluto com a homogeneização de um raspado do crescimento da rampa do ágar com $0,5 \mathrm{~mL}$ de AFT em um novo tubo estéril, obtendo um inócuo que servirá a toda a bioquímica.

A bioquímica do B. Cereus é composta de 8 testes que devem ser feitos com muita calma e atenção, sendo eles teste de utilização anaeróbia da glicose; teste de decomposição da Tirosina; teste de Voges Proskauer; teste de redução do nitrato; teste da resistência a lisozima; teste de motilidade; verificação do crescimento rizoide e verificação de atividade hemolítica. Caso seja confirmada sua presença no alimento analisado, o resultado será expresso em UFC/g ou mL segundo a equação:

Se forem confirmadas as colônias o resultado deverá ser expresso em UFC/g e calculado através da fórmula:

$\mathrm{A} \times \mathrm{B} \times \mathrm{C} \times \mathrm{D} \times 10=\mathrm{X} \mathrm{UFC} / \mathrm{g}$.

Onde $\mathrm{A}=$ número de colônias confirmadas; $\mathrm{B}=$ número de colônias submetidas à confirmação; $\mathrm{C}=$ número de colônias contidas na placa; $\mathrm{D}=$ diluição da placa.

\section{Staphylococcus spp coagulase positiva}

Para Silva et al. (2010), são cocos Gram positivos, anaeróbios facultativos, e apresentam maior crescimento em condições aeróbias. São catalase positivas, mesófilas, pois sua faixa de temperatura de crescimento varia entre $7^{\circ} \mathrm{C}$ e $47,8^{\circ} \mathrm{C}$ e algumas bactérias desse gênero podem produzir enterotoxinas entre $10^{\circ} \mathrm{C}$ e $46^{\circ} \mathrm{C}$. São facilmente destruídos na pasteurização ou cocção de alimentos, porém suas toxinas são termo resistentes. Suas cepas são resistentes ao calor, mas são facilmente destruídas na pasteurização ou cocção, ao contrário de suas toxinas que suportam tratamentos térmicos tão severos como a esterilização de alimentos de baixa acidez.

Ainda segundo o autor, a doença transmitida por esse microrganismo é uma intoxicação provocada pela ingestão de suas toxinas formadas no alimento. Essas toxinas são proteínas resistentes à cocção e às enzimas proteolíticas, seus sintomas são evidenciados entre 2 a 6 horas após a ingestão e incluem náuseas, vômito, cólica, prostração, queda da pressão arterial e da temperatura. Geralmente o indivíduo acometido consegue se recuperar em torno de dois dias, e são raras as complicações ou morte.

De acordo com o Manual de Métodos de Análise Microbiológica de Alimentos e Água (Silva et al., 1997), a metodologia referenciada para a identificação desse microrganismo em amostras de alimentos necessita semear $0,1 \mathrm{~mL}$ das diluições decimais $10^{-2}, 10^{-3}, 10^{-4} \mathrm{em}$ placa de Agar Baird Parker e incubar as placas invertidas na estufa de $35^{\circ} \mathrm{C}$ por 48 horas e observar se há o crescimento de colônias negras, com halo ao redor.

Em caso positivo faz-se necessária a confirmação pelo teste da coagulase, para o qual são selecionadas de 3 a 5 colônias que deverão ser repicadas com uma alça de platina para um tubo com caldo brain heart infusion (BHI), incubadas a $35^{\circ} \mathrm{C}$ por 24 horas, e em seguida são retirados $0,2 \mathrm{ml}$ de cada tubo e repicados, respectivamente, para tubos contendo $0,5 \mathrm{~mL}$ de plasma de coelho. Em seguida deve-se incubar na estufa a $35^{\circ} \mathrm{C}$ por 6 horas, fazendo a leitura a cada hora avaliando a presença ou não de coágulo e seu grau numa escala de 0 a 4 . Se forem confirmadas as colônias o resultado deverá ser expresso em UFC/g e calculado através da fórmula:

A x B x C x D x $10=$ X UFC/g.

Onde $\mathrm{A}=$ número de colônias confirmadas; $\mathrm{B}=$ número de colônias submetidas à confirmação; $\mathrm{C}=$ número de colônias contidas na placa; $\mathrm{D}$ = diluição da placa

\section{Considerações finais}

A Medicina Veterinária tem um papel muito especial na Saúde Pública, com relação à produção de alimentos e o seu controle de qualidade em todas as fases da cadeia produtiva, seja no manejo e criação dos animais de diversas espécies, seja no seu abate e processamento dos seus produtos e subprodutos, na prevenção, erradicação e controle de zoonoses, vigilância epidemiológica e ambiental. Nesse âmbito os conhecimentos específicos de microbiologia de alimentos compreendem uma área de especialização para quem deseja contribuir para uma melhor qualidade de vida da população. 
Com o aumento da população e o aumento da produção de alimentos em larga escala, aumenta também a necessidade de melhorar o controle da qualidade desses alimentos, visando reduzir a exposição de grande parcela da população aos riscos inerentes a ingestão de alimentos ou água contaminados.

O controle microbiológico e sensorial é fundamental para a garantia da qualidade desses alimentos disponibilizados para a população. E o padrão de qualidade do serviço prestado pelo laboratório influencia diretamente na confiabilidade dos resultados das análises realizadas prevenindo doenças e promovendo a saúde da população em geral, garantindo a eficiência na identificação desses patógenos acerca do monitoramento de riscos relacionados ao consumo de alimentos que possam causar dano para a saúde pública, ocasionando surtos de Doenças Transmitidas por Alimentos, sejam elas de origem infecciosa ou crônicas.

Através da combinação dos conhecimentos de epidemiologia, tecnologia de alimentos, zoonoses, microbiologia, imunologia, vigilância sanitária, doenças infecciosas, entre outros, trata-se de uma das principais etapas da estratégia de prevenção de doenças, gerando retorno efetivo dessa ação diretamente para a sociedade e sua influência na melhora da qualidade de vida no dia a dia das pessoas.

Portanto é de suma importância que os profissionais que atuam na área estejam constantemente atualizados, e para isso faz-se necessária a disponibilidade de conteúdo de qualidade para que tenham acesso às principais informações necessárias à sua prática cotidiana eficiente.

\section{Referências}

Ahmed, A. M., \& Shimamoto, T. (2014). Isolation and molecular characterization of Salmonella enterica, Escherichia coli O157:H7 and Shigella spp. from meat and dairy products in Egypt. International Journal of Food Microbiology, 168-169(0), 57-62. DOI: http://dx.doi.org/10.1016/j.ijfoodmicro.2013.10.014

ANVISA. (2013). Manual de microbiologia clínica para o controle de infecção relacionada à assistência à saúde (D. e identificação de bactérias de importância médica (ed.); Vol. 9). Ministério da Saúde.

Araújo, J. M. A. (2004). Química de alimentos: teoria e prática. In Química de alimentos: teoria e prática. Universidade Federal de Viçosa Imprensa Universitaria.

BRASIL, ANVISA - Agência Nacional de Vigilância Sanitária. RDC nº 12 de 02 de jameiro de 2001. Aprova o Regulamento Técnico sobre padrões microbiológicos para alimentos. D.O.U. - Diário Oficial da União, DF, 10 de janeiro de 2001.

BRASIL, MS - Ministério Da Saúde. Portaria no 3.204 de 20 de outubro de 2010. Aprova Norma Técnica de Biossegurança para Laboratórios de Saúde Pública.D.O.U. - Diário oficial da união, DF, 21 de outubro de 2010.

BRASIL, MS-Ministério da saúde. Manual Técnico de Diagnóstico Laboratorial da Salmonella spp. Brasília - DF. 2011.

BRASIL, MAPA - Ministério Da Agricultura Pecuária E Abastecimento. Portaria $n^{\circ} 370$ de 4 de setembro de 1997. Estabelece os padrões de qualidade e identidade do leite UHT. D.O.U. - Diário Oficial da União, DF, 08 de setembro de 1997.

BRASIL, MAPA - Ministério da agricultura pecuária e abastecimento. Decreto ${ }^{\circ} 6.871$ de 04 de junho de 2009. Regulamenta a Lei $\mathrm{n}^{\circ} 8.918$ de 14 de julho de 1994, que dispõe sobre a padronização, classificação, o registro, a inspeção, a produção e a fiscalização de bebidas. D.O.U. - Diário Oficial da União, DF, 05 de junho de 2009.

BRASIL, SVS/MS - Ministério da saúde. Portaria no 204 de 17 de fevereiro de 2016. Define a Lista Nacional de Notificação compulsória de doenças, agravos e eventos de saúde pública nos serviços de saúde públicos e privados em todo o território nacional, nos termos do anoexo, e dá outras providências. D.O.U. - Diário Oficial da União, DF,19 de fevereiro de 2016.

Bruha, W., Braden, K., Wallace, B., Schwartz, M., \& Branham, L. (2014). Prevalence and serogroup type of Salmonella spp. in feedlot lamb fecal and hide samples before and after harvest. Meat Science, 96(1), 488. DOI: http://dx.doi.org/10.1016/j.meatsci.2013.07.142 
Forsythe, S. J. (2013). Microbiologia da segurança dos alimentos. Artmed.

Franco, B. D. G. M., \& Landgraf, M. (2003). Microbiologia dos alimentos. In Microbiologia dos alimentos. Atheneu.

Franco, B., \& Landgraf, M. (1996). Microbiologia dos alimentos. In São Paulo: Atheneu (Vol. 182). Atheneu Editora.

Hasler, C. M. (1998). Functional foods: their role in disease prevention and health promotion. Fodd Technology, 52, 63-147.

Hocquette, J. F., Richardson, R. I., Prache, S., Medale, F., Duffy, G., \& Scollan, N. D. (2005). The future trends for research on quality and safety of animal products. Italian Journal of Animal Science, 4(SUPPL. 3), 49-72. $\quad$ http://www.scopus.com/inward/record.url?eid=2-s2.033645815104\&partnerID=40\&md5=21376bffa8274328b57c065975cb09ef. https://doi.org/10.4081/ijas.2005.3s.49

Iamanaka, B. T., Oliveira, I. S., \& Taniwaki, M. H. (2013). Micotoxinas em alimentos. Anais Da Academia Pernambucana de Ciência Agronômica, 7, 138-161.

Krämer, N., Löfström, C., Vigre, H., Hoorfar, J., Bunge, C., \& Malorny, B. (2011). A novel strategy to obtain quantitative data for modelling: Combined enrichment and real-time PCR for enumeration of salmonellae from pig carcasses. International Journal of Food Microbiology, 145, Suppl(0), S86S95. DOI: http://dx.doi.org/10.1016/j.ijfoodmicro.2010.08.026

Malacrida, A. M., Dias, V. H. C., \& Lima, C. L. (2017). Perfil epidemiológico das doenças bacterianas transmitidas por alimentos no Brasil. Revista de Ciência Veterinária e Saúde Pública, 4, 158-162.

Melo, E. S., Amorim, W. R., Pinheiro, R. E. E., Corrêa, P. G. N., Carvalho, S. M. R., Santos, A. R. S. S., Barros, D. S., Oliveira, E. T. A. C., Mendes, C. A., \& Sousa, F. V. (2018). Doenças transmitidas por alimentos e principais agentes bacterianos envolvidos em surtos no Brasil. PUBVET, 12(10), 1 9. DOI: https://doi.org/10.31533/pubvet.v12n10a191.1-9

Silva, N., Neto, R. C., Junqueira, V. C. A., Silveira, N. F. A., Aniwaki, M. H., Dos Santos, R.F.S. \& Gomes, R.A.R (2010). Manual de Métodos de Análise Microbiológica de Alimentos e da Água (E. Varela (ed.); Vol. 1). Varela, São Paulo 624 p..

Tortora, G. J., Berdell, R. F., \& Christine, L. C. (2017). Microbiologia. Artmed.

Welker, C. A. D., Both, J. M. C., Longaray, S. M., Haas, S., Soeiro, M. L. T., \& Ramos, R. C. (2010). Análise microbiológica dos alimentos envolvidos em surtos de doenças transmitidas por alimentos (DTA) ocorridos no estado do Rio Grande do Sul, Brasil. Revista Brasileira de Biociências, 8(1), 44-48

\section{Histórico:}

Recebido: 14 de julho de 2020.

Aprovado: 11 de agosto de 2020.

Disponível online: 12 de dezembro de 2020
Licenciamento: Este artigo é publicado na modalidade Acesso Aberto sob a licença Creative Commons Atribuição 4.0 (CC-BY 4.0), a qual permite uso irrestrito, distribuição, reprodução em qualquer meio, desde que o autor e a fonte sejam devidamente creditados. 